\title{
ATENÇÃO ONLINE DE ARTIGOS DO PORTAL PERIÓDICOS UFMG: Análise dos dados do Facebook
}

\author{
Ronaldo Ferreira de Araújo \\ Universidade Federal de Alagoas \\ ronaldfa@gmail.com \\ Tiago Rodrigo Marçal Murakami \\ Universidade de São Paulo \\ trmurakami@gmail.com \\ Sergio Dias Cirino \\ Universidade Federal de Minas Gerais \\ sergiocirino99@yahoo.com \\ Carla Cristina Vieira de Oliveira Autor \\ Universidade Federal de Minas Gerais \\ cvieirao@gmail.com
}

\begin{abstract}
Resumo
Discorre sobre o portal de periódicos da Universidade Federal de Minas Gerais como uma das ações da política de periódicos desta instituição e apresenta alguns de seus resultados. Como parte das ações de desenvolvimento do portal e com vistas a reflexão sobre dados de interação do Facebook como indicativo de atenção online e sobre métricas alternativas da produção científica, a presente pesquisa analisa, por meio de um estudo empírico de caráter exploratório, o impacto social de artigos de revistas científicas do Portal Periódicos UFMG segundo seus dados de curtidas, compartilhamentos e comentários. Foram analisados 46 periódicos do portal, com publicação no período de 2010 a 2017, os quais forneceram 6.437 artigos, sendo que apenas 543 deles possuíam dados de interação. A atenção online é caracterizada segundo sua distribuição por faixa de interação, área de conhecimento, período e analisada pelo desempenho de revistas e artigos.
\end{abstract}

\section{Palavras-chave}

Altmetria. Atenção online. Facebook. Portal Periódicos UFMG.

\section{INTRODUÇÃO}

A avaliação do impacto social por meio de métricas alternativas de publicações de resultados parciais ou finais de pesquisa tem sido cada vez mais buscada pela comunidade interessada em complementar os estudos tradicionais de avaliações de desempenho com base em indicadores quantitativos específicos (p. ex. produtividade científica, número de citações e fatores de impacto) que trazem consigo inúmeras críticas, sobretudo devido à sua negligência dos aspectos qualitativos e subjetivos do desempenho científico.

No contexto de uma ciência aberta que se utiliza dos recursos digitais para potencialização das atividades de pesquisa, a fim de que estas ocorram de forma mais democrática e participativa, a altmetria (altmetrics) se apresenta como um campo promissor para se pensar essa complementariedade e pode contribuir no levantamento de indicadores que auxiliam na compreensão do interesse público pela ciência ao atentar sobre a circulação da informação científica na web social e 
perceber as métricas das interações que ela gera.

Devido ao grande número de mídias sociais e plataformas como Facebook, Twitter, YouTube, Wikipédia e outros que passam a ser consideradas como fonte de dados altmétricos, e tendo em vista que possuem suas particularidades, tem sido cada vez mais necessários estudos que compreendem o que cada uma delas representa para a comunicação e divulgação científica.

Diante disso o presente estudo tem por objetivo refletir sobre uma dessas mídias, o Facebook, compreender as interações deste dispositivo informacional, a saber, as curtidas, compartilhamentos e comentários, enquanto elementos de atenção online e fonte de dados altmétricos, e dialogar tais reflexões com uma análise empírica que considerou revistas científicas do Portal Periódicos da Universidade Federal de Minas Gerais (UFMG).

Após algumas considerações conceituais, o portal é apresentado como uma das ações da política de periódicos da UFMG e descrito a partir de um breve histórico e segundo alguns aspectos de visibilidade, indexadores e distribuição por área de conhecimento. Para a avaliação do portal, as métricas alternativas de atenção online e de interação têm sido pensadas como possibilidade de verificação do interesse público e da comunidade científica pelos periódicos do portal e de seu impacto social.

As interações ou ações de curtir, compartilhar e comentar no Facebook são vistas como apropriações simbólicas e podem indicar intenções distintas. Quando cientistas e pesquisadores "curtem" algo, dão visibilidade e audiência a conteúdos relevantes, o que pode ser considerado um indicador valioso do impacto de trabalhos acadêmicos, uma ação positiva de gostar de um conteúdo e consequentemente transmitilo para sua rede (RINGELHAN; WOLLERSHEIM; WELPE, 2015) o que pode ser estendido às ações de compartilhar e de comentar.

O compartilhamento no Facebook pode ser considerado um bom filtro de informação funcionando como recomendações e o comentário expressa um indicativo de receptividade, podendo indicar avaliações e debates em torno de artigos recém-publicados. Assim, "artigos bastante compartilhados logo após sua publicação são aqueles de grande apelo para uma área" (IAMARINO, 2013) e os mais "comentados" enfatizam que o apelo tem mobilizado a discussão (BORNMANN, 2014).

\section{PORTAL DE PERIÓDICOS UFMG: UMA DAS AÇÕES DE UMA POLÍTICA CIENTÍFICA INSTITUCIONAL}

Por meio dos recursos da tecnologia da informação surgem os portais de periódicos científicos das universidades, que possibilitam a integração de sistemas, com trabalho inovador e interdisciplinar de infraestrutura da equipe, de colaboradores, autores e demais envolvidos. Essa estrutura contribui para a melhoria a visibilidade das instituições e para o sistema de comunicação científica (RODRIGUES; FACHIN, 2010). Como lembram Gulka e Lucas (2017) os portais agrupam os periódicos institucionais que estavam dispersos pela rede, auxiliandoos nos elementos de gestão de qualidade. Organizar diversos periódicos de uma mesma instituição exige uma estrutura que viabilize as ações para o uso de uma única plataforma, enquanto possibilita a definição de uma responsabilidade institucional para um grupo de periódicos, como uma metaeditora (RODRIGUES; FACHIN, 2008).

Os portais de periódicos possibilitam o agrupamento dos periódicos científicos da universidade, que outrora se encontravam dispersos pelas unidades acadêmicas. Além de possibilitar a recuperação rápida de um periódico, o portal possibilita a padronização das informações e se diferenciam dos repositórios por, em seus conteúdos possuírem artigos de autores, em grande 
parte, externos ${ }^{1}$ à instituição publicadora (GUILKA; LUCAS, 2017). E a presença dos portais de periódicos nas universidades permite a integração, a colaboração e personalização dos recursos de tecnologias da informação e comunicação e da web. (RODRIGUES; FACHIN, 2010)

Rodrigues e Fachin (2010) ressaltam a importância de uma instituição apoiar a implantação do portal de periódicos. Elas sugerem que a institucionalização ocorra por meio da alta direção da instituição e pela comunidade científica. Sendo assim, o fluxo de trabalho e os agentes envolvidos na estruturação de um portal de periódicos, para estas autoras, devem possuir em sua estrutura: 1) comunicação científica, periódicos com acesso livre e arquivos abertos, recursos tecnológicos a serem adotados e institucionalização do Portal; 2) equipe técnica interdisciplinar, editores $\mathrm{e}$ equipe editorial de cada periódico, dirigentes a instituição e instituições de fomento e avaliação, 3) editores, equipe técnica, coordenação do portal, dirigentes institucionais e comunidade geral composta por alunos, professores e demais usuários; 4) equipe multidisciplinar composta por designer, analista de sistema, bibliotecários, profissional de segurança e preservação da informação, com diretrizes e políticas institucionais definidas e sua manutenção. As autoras ressaltam que só com o envolvimento da comunidade nessa estrutura as ações poderão ser realizadas.

No que tange as ações que devem ser desenvolvidas pelos portais de periódicos científicos, Rodrigues e Fachin (2008) ressaltam: a formação e capacitação de editores; a organização das questões técnicas e organizacionais e a supervisão dos trabalhos dos periódicos. Essas ações foram complementadas por Rodrigues e Fachin (2010), que sugerem a apresentação do projeto do portal pela instituição; formação e

\footnotetext{
${ }^{1}$ Para um periódico científico ser de qualidade, entre tantos critérios, ressalta-se aqui o fato da importância da publicação ser exógena, que especifica que melhor será avaliado o periódico que possua autores externos à instituição responsável pela publicação.
}

capacitação constante da equipe técnica, editores e demais envolvidos no processo do Portal; estruturação e organização das questões técnicas e operacionais que envolvem o processo de implantação; avaliação e conferência da migração de cada periódico, com a adoção dos padrões e políticas estabelecidas e acompanhamento e reunião constantes para socialização do processo.

Observa-se ainda que os objetivos e políticas para o portal devem ser estabelecidos em concordância com o perfil da instituição. A institucionalização de um portal de periódicos possibilita a estrutura para um bom funcionamento, tanto no que tange aos recursos físicos e financeiros, quanto a disponibilidade e o acesso dos periódicos quanto a sua segurança. Garrido e Rodrigues (2010) destacam a importância da institucionalização para um portal de periódicos científicos, por fornecer credibilidade seja através da identidade visual, dos conselhos e políticas editoriais, bem como na preservação de dados, padrões, suporte técnico e treinamentos.

Com o objetivo de padronizar as informações referentes a editoração científica dispersas na comunidade científica da Universidade Federal de Minas Gerais (UFMG), surgiu o portal de periódicos, como uma das oito ações presentes na Política de Periódicos UFMG lançada publicamente na instituição no dia 22 de outubro de 2015.

Além do portal de periódicos, compõem a política as seguintes ações: a elaboração de um diretório de periódicos ${ }^{2}$; a implementação da avaliação sistemática dos periódicos; o apoio à formação de editores e demais envolvidos na edição de periódicos; o incentivo à atuação dos editores no processo de internacionalização dos periódicos; incentivo e acompanhamento dos processos de indexação nacional e internacional; o resgate histórico de ações anteriores de

\footnotetext{
2 A primeira versão do diretório de periódicos foi publicada em 2016 e está disponível em < https://www.ufmg.br/periodicos/wpcontent/files/2015/08/Diret $\%$ C3\%B3rioperi $\%$ C3\%B3dicos-UFMG-2.pdf>
} 
qualificação dos periódicos e a criação da incubadora de periódicos. Evidenciou-se o exposto por Rodrigues e Fachin (2010) sobre a importância de a instituição apoiar a implantação do portal de periódicos, pois assim ocorreu na UFMG: uma parceria com a administração central desde o primeiro momento.

Ressalta-se que a compreensão acerca da importância de uma política de periódicos para a universidade esteve presente na proposta de campanha do atual reitorado. Em 2014, quando esses gestores assumiram a reitoria, a política de periódicos para a universidade passou a ser trabalhada como uma das atividades desenvolvidas da Diretoria de Produção Científica, setor este pertencente a Pró-Reitoria de Pesquisa.

Os anos de 2014 e 2015 foram fundamentais para a política de periódicos, pois foi uma atividade da política $\mathrm{O}$ levantamento nas unidades acadêmicas dos periódicos existentes e ativos, fato este até o momento desconhecido para a comunidade acadêmica como um todo. Diante do cenário encontrado, optou-se por firmar a política em dois pilares: inclusão e excelência, com a implantação, naquele primeiro momento, de cinco critérios básicos para a seleção dos periódicos que pertenceriam ao portal. Desta seleção, agrupou-se 62 periódicos científicos, disponíveis no site $<$ https://www.ufmg.br/periodicos/>.

Os cinco primeiros critérios foram: 1 ) de pertencimento, ser períodico editado por membro da UFMG; 2) de caracterização, ter International Standard Serial Number (ISSN) (impresso ou eletrônico); 3) de disponibilização, ter URL ativa; 4) de garantia de qualidade, ter comitê editorial; e 5) de atualidade, ter publicado pelo menos um número em 2013. Os primeiros critérios foram mais flexíveis, em função da necessidade de inclusão das revistas, mas recentemente foi realizado um estudo da equipe do portal, submetido à apreciação da comunidade científica ao longo do ano de 2017 e que culminou em mais 12 critérios até o momento, que serão revistos frequentemente, tendo por parâmetro as demandas das agências de fomento e dos indexadores.

Os novos critérios acrescentados à política, que permitem a manutenção do periódico no portal e/ou a entrada de novos periódicos são: 1) a responsabilidade interinstitucional pelos periódicos passou a ser permitida, sendo que ocasionalmente as revistas poderão não ter um membro da UFMG como editor; 2) a exigência de explicitação da tipologia de artigos publicados, com predominância de artigo inédito; 3) ter somente ISSN eletrônico e manter essa informação explícita; 4) Acesso Aberto; 5) informação sobre a periodicidade adotada; 6) ter publicado regularmente todos os números relativos aos dois anos anteriores ao ano corrente; 7) possuir e tornar explícito as informações referente ao foco, escopo, diretrizes para os autores e processo de avaliação de revisão por pares; 8) possuir conselho editorial com presença de membros de instituições externas à UFMG, com nome completo e afiliação; 9) estar indexado em pelo menos dois indexadores; 10) os artigos devem possuir nome, e-mail e afiliação dos autores; 11) informação sobre as normas de publicação adotadas; 12) possuir no site, de forma explícita, o contato com a publicação.

Dentre os serviços realizados pela equipe do portal de periódicos destacam-se: a capacitação dos editores, presente no primeiro ciclo de formação a editores e equipe editoriais, realizado no primeiro semestre de 2016, com cinco palestras e uma oficina de capacitação. Além desta ação, outros eventos foram realizados ao longo dos anos de 2016/2017, com o propósito de capacitar e fomentar os responsáveis pelos periódicos e demais envolvidos na editoração científica.

Outra ação realizada frequentemente é a avaliação sistemática das publicações, o que também possibilitou a atualização dos critérios explicitados acima e a criação da incubadora de periódicos, espaço esse dedicado para orientação, acompanhamento e treinamento de editores em questões específicas do seu cotidiano. No que tange a visibilidade dos periódicos científicos do 
portal de periódicos em indexadores, estes podem ser observados na Tabela 1.

Tabela 1. Contexto dos periódicos científicos do Portal de Periódicos UFMG.

\begin{tabular}{|c|c|}
\hline \multicolumn{2}{|c|}{ Visibilidade dos Periódicos Científicos } \\
\hline Perfil no Google acadêmico & 30 \\
\hline Indexados na Web of Science & 9 \\
\hline Indexados na SciELO & 9 \\
\hline Indexados na Scopus & 5 \\
\hline Indexados na Latindex & 39 \\
\hline Indexados no DOAJ & 19 \\
\hline
\end{tabular}

Fonte: dados coletados pelo portal de periódicos UFMG (2017)

A presença nos indexadores dos periódicos do portal de periódicos UFMG vem sendo monitorada pela equipe do portal e observou-se a maior presença dos periódicos nos indexadores Latindex e DOAJ. Acredita-se que isto é fruto do primeiro ciclo de formação de editores, que com a palestra: "Critérios para indexação em bases de dados" incentivou os editores a buscar aumentar os indexadores das publicações, buscando os indexadores com requisitos mais simples e a melhorar as publicações visando atender os requisitos mais complexos, tendo uma meta a se atingir para cada indexador desejado.

Numa breve contextualização dos periódicos científicos, observa-se que dos 62 periódicos atualmente presentes no portal, apenas 26 atribuíram o $\mathrm{DOI}^{3}$ aos seus conteúdos. Destes nove recebem acesso a esse identificador por serem indexados no SciELO e o restante, por recursos próprios de sua unidade. O portal de periódicos tem como meta para 2018 articular recursos financeiros para auxiliar o restante dos

\footnotetext{
3 Digital Object Identifier (DOI), identificador internacionalmente aceito para documentos digitais, possibilitando a identificação, localização e descrição de entidades digitais. O DOI deve ser atribuído ao conteúdo pelo editor. (BRITO et al., 2016)
}

periódicos da instituição a atribuírem esse identificador ao conteúdo de suas publicações.

Outro desafio do portal de periódicos tem sido unificar o acesso aos periódicos científicos em uma única plataforma SEER ${ }^{4}$ na instituição. Atualmente dos 62 periódicos, 17 já foram migrados para a plataforma SEER central da instituição. Esse trabalho tem sido feito aos poucos, pois envolve a mudança da cultura da instituição, visto que muitos periódicos estão alocados há anos na plataforma da unidade, com o apoio do setor de tecnologia da informação desta. A equipe tem realizado o contato com cada unidade e tentando incentivar a mudança por unidade. O objetivo é trazer o que está disperso para o mesmo ambiente, o que facilitará a segurança e atualizações das versões do software. Deste universo, só não se pretende intervir nos periódicos que estão na SciELO. Os periódicos atualmente estão dispersos nas áreas de conhecimento apresentadas no Gráfico 1. 
Gráfico 1. Periódicos científicos presentes no Portal UFMG por área do conhecimento.

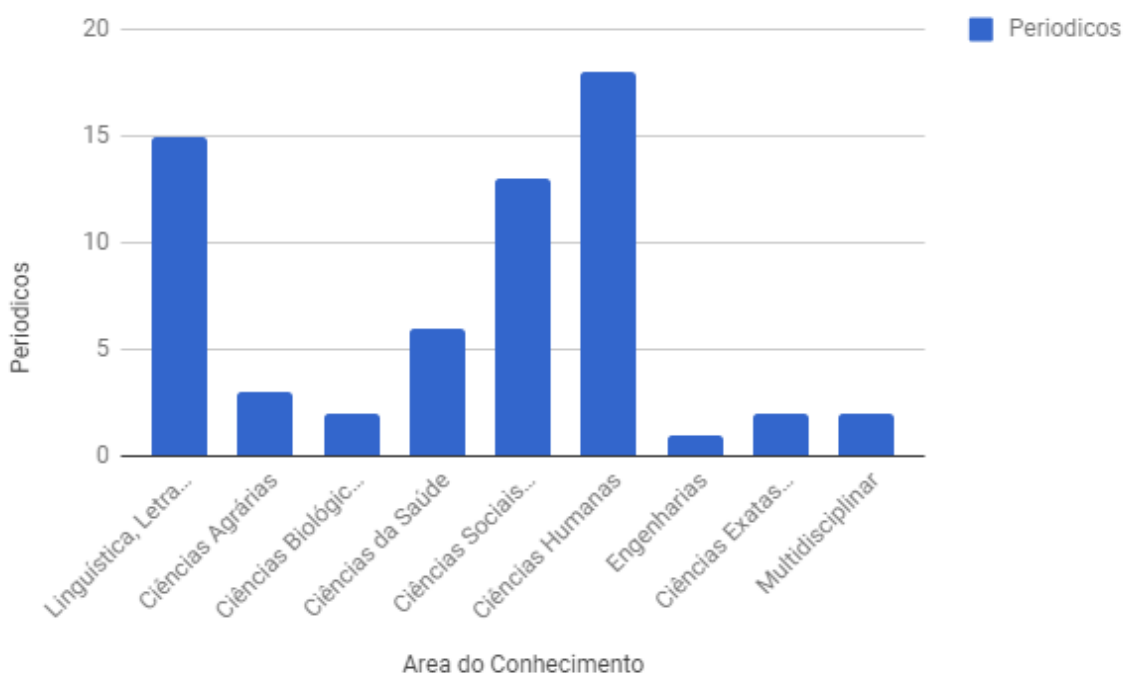

Fonte: dados coletados pelo portal de periódicos UFMG (2017)

Observa-se a presença significativa das áreas de Ciências Humanas; Linguísticas, Letras e Artes e Ciências Sociais Aplicadas, embora, tem-se a representatividade de todas as áreas do conhecimento, mesmo que pequena. Atualmente, a incubadora de periódicos possui quatro periódicos, que serão avaliados neste semestre segundo os novos critérios, para que integrem o portal de periódicos neste ano de 2018. Destes, três são da área de Ciências Sociais Aplicadas e um de Linguísticas, Letras e Artes. Com relação ao Qualis, o portal de periódicos, possui revistas em todos os estratos conforme apresentado no Gráfico 2.

Observa-se que três periódicos científicos não possuem Qualis, já que não publicaram artigos com autores vinculados a uma pós-graduação. Destes, dois são periódicos que publicam artigos de discentes e um periódico técnico. $\mathrm{Na}$ última avaliação, referente ao triênio 2013-2016, o estrato B2 mais comum entre os periódicos do portal.

Gráfico 2. Qualis dos Periódicos científicos presentes no Portal UFMG

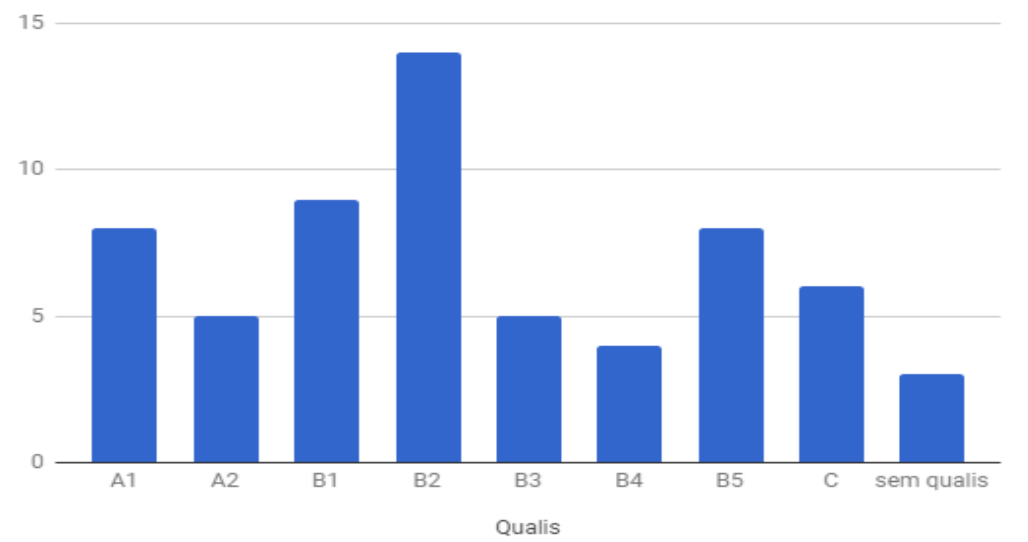

Fonte: dados coletados pelo portal de periódicos UFMG (2017)

No último levantamento da periodicidade e da regularidade dos realizado no final do segundo semestre de 
$2017^{5}$, observou-se que apenas 38 periódicos estavam regulares conforme a periodicidade adotada. Essa realidade tem feito a equipe do portal de periódicos pensar em novas ações e estratégias a serem realizadas ao longo deste ano com objetivo de auxiliar os editores neste desafio. Apesar das dificuldades de manter a periodicidade, têm-se dois periódicos que estão publicando em fluxo contínuo. No segundo semestre de 2017, 16 periódicos foram contemplados com recursos financeiros no edital de fomento da FAPEMIG $^{6}$. A incubadora de periódicos auxiliou muitos editores na submissão de projetos nesta avaliação. São muitos os desafios sentidos pela equipe do portal de periódicos UFMG, mas em tão poucos anos de política são muitos os resultados positivos que os editores da universidade e a equipe estão colhendo.

No âmbito das ações de qualificação do portal é que se concentram, dentre outras atividades, a agregação de indicadores de atenção, visibilidade, acesso e, mais recentemente, de métricas alternativas de atenção online, ou seja, que mensuram o interesse público e acadêmico pelas revistas do portal e indicam interações com os artigos produzidos por seus periódicos. Essa frente tem sido discutida e elaborada em parceria com o Laboratório de Estudos Métricos da Informação na Web (Lab-iMetrics) ${ }^{7}$ da Universidade Federal de Alagoas, na linha de pesquisa: "Ciência 2.0 e os aportes da altmetria".

\section{MATERIAL E MÉTODO}

Trata-se de uma pesquisa exploratória de abordagem quantitativa descritiva tendo como universo empírico artigos de revistas científicas presentes no Portal Periódicos UFMG. De um total de 62 periódicos científicos presentes no portal, 57,6\% não possui um identificador permanente, no caso,

\footnotetext{
${ }^{5}$ Esta análise é realizada sempre nos fins de semestre, esse é o dado mais atual.
}

${ }^{6}$ Fundação de Amparo à Pesquisa do Estado de Minas Gerais < http://www.fapemig.br/> o DOI, solução necessária para o monitoramento de métricas alternativas pelas ferramentas atualmente disponíveis no mercado.

Para contornar a ausência desse padrão comum de identificação exigido pelos serviços atuais de aferição de altmetria, a coleta de dados altmétricos do Facebook seguiu as orientações metodológicas de Araújo, Murakami e Andrade (2016) na utilização de uma solução via Application Program Interface (API) que considera apenas os periódicos suportados pelo protocolo OAI-PHM utilizado no SEER/OJS, o que correspondeu a 52 revistas, das quais seis foram desconsideradas por apresentarem erro na versão do SEER/OJS e impedirem a coleta dos metadados da produção.

Sendo assim, foram coletados e analisados, na última quinzena de outubro de 2017, os artigos de 46 revistas do portal, tendo como recorte temporal os anos de 2010 a 2017, uma vez que a literatura expressa que a altmetria é adequada para aferição de impacto de publicações recentes.

As consultas foram parametrizadas pelas URLs principal e secundária de todos os artigos das 46 revistas, com sua representação quantitativa em termos de "curtidas", "compartilhamentos" e "comentários". Os dados são apresentados segundo o volume quantitativo por área de conhecimento, por revistas, para que, em seguida, se discorra sobre os artigos com maior atenção online.

\section{DISCUSSÃO DOS RESULTADOS}

No período analisado (2010 a 2017) os 46 periódicos do portal somavam 6.437 artigos, dos quais apenas 543 (8,43\%) obtiveram ao menos uma interação no Facebook. Os 543 artigos forneceram para análise um total de 11.265 dados de atenção, com uma média de $20,74 \%$ de interação por artigo. A Tabela 2 apresenta a distribuição

\footnotetext{
Informações sobre o Lab-iMetrics: http://dgp.cnpq.br/dgp/espelhogrupo/52070194506 70905
} 
dos artigos por faixa de interação e a Tabela 3 por período de interação (dois anos).

Tabela 2. Artigos por faixa de interação

\begin{tabular}{|l|r|r|}
\hline Faixa de interação & Artigos & (\%) \\
\hline Mais de 100 & 24 & 4,42 \\
\hline De 50 a 99 & 38 & 7,00 \\
\hline De 10 a 49 & 156 & 28,73 \\
\hline Menos de 10 & 325 & 59,85 \\
\hline Total & $\mathbf{5 4 3}$ & $\mathbf{1 0 0}$ \\
\hline
\end{tabular}

Fonte: dados da pesquisa (2017)

É possivel perceber que a maioria dos artigos obteve menos de 10 interações $(59,8 \%)$ e que só um número reduzido alcançou mais de 100 interações (4,4\%). No que se refere a essa distribuição pelos anos analisados, verificou-se um movimento crescente que corrobora a premissa de que artigos recém-publicados costumam atingir uma maior pontuação altmétrica.

A distribuição da atenção online obtida no Facebook por área de conhecimento indica as Ciências Sociais Aplicadas com 49,9\% do total, seguida da área de Linguística, Letras e Artes com 29,4\%, das Ciências da Saúde com 7,03\% e das Ciências Humanas e Exatas e da Terra,
Tabela 3. Artigos por período de interação

\begin{tabular}{|l|r|r|}
\hline Anos & Artigos & (\%) \\
\hline $2010-2011$ & 47 & 8,66 \\
\hline $2012-2013$ & 141 & 25,97 \\
\hline $2014-2015$ & 148 & 27,26 \\
\hline $2016-2017$ & 207 & 38,12 \\
\hline Total & $\mathbf{5 4 3}$ & $\mathbf{1 0 0}$ \\
\hline
\end{tabular}

Fonte: dados da pesquisa (2017)

com 6,85\% e 6,42\%, respectivamente. As áreas Interdisciplinar e Ciências Agrárias tiveram o menor desempenho com $0,31 \%$ e 0,04\%, enquanto as Engenharias não apresentaram nenhuma incidência.

Os 11.265 dados altmétricos refletem uma atenção online distribuída em 8.233 curtidas (C1), 1.493 compartilhamentos (C2) e 1.539 comentários (C3) obtidos pelos periódicos, cuja distribuição é representada na Tabela 4, ordenados pela posição (\#) do periódico, segundo seu desempenho na soma total das interações. (Para facilitar a visualização, as revistas com até 99 interações foram contabilizadas, mas não constam nominadas na tabela).

Tabela 4. Distribuição dos periódicos por interação no Facebook

\begin{tabular}{lrrrrr}
\hline Nome do Periódico & C1 & C2 & C3 & Total & (\%) \\
\hline Perspectivas em Ciência da Informação & 1071 & 323 & 252 & 1646 & 14,61 \\
Revista da Faculdade de Direito da UFMG & 1082 & 135 & 102 & 1319 & 11,71 \\
Revista Brasileira de Estudos Políticos & 950 & 147 & 97 & 1194 & 10,60 \\
PÓS: Rev. Prog. Pós-graduação Artes da EBA/UFMG & 522 & 79 & 68 & 669 & 5,94 \\
Revista Geonomos & 453 & 38 & 80 & 571 & 5,07 \\
Texto Livre: Linguagem e Tecnologia & 353 & 36 & 173 & 562 & 4,99 \\
LICERE - Rev. Prog. Pós-graduação Interdisc. Est. Lazer & 391 & 50 & 50 & 491 & 4,36 \\
Em Tese & 335 & 74 & 80 & 489 & 4,34 \\
Aletria: Revista de Estudos de Literatura & 311 & 68 & 66 & 445 & 3,95 \\
Revista Docência do Ensino Superior & 290 & 37 & 41 & 368 & 3,27 \\
Arquivo Maaravi: Rev. Dig. Est. Judaicos da UFMG & 241 & 64 & 53 & 358 & 3,18 \\
Revista Brasileira de Estudos do Lazer & 224 & 21 & 59 & 304 & 2,70 \\
Cadernos Benjaminianos & 199 & 38 & 51 & 288 & 2,56 \\
Revista do Centro Acadêmico Afonso Pena & 197 & 68 & 23 & 288 & 2,56 \\
O Eixo e a Roda: Revista de Literatura Brasileira & 223 & 22 & 25 & 270 & 2,40
\end{tabular}

Ci. Inf. Rev., Maceió, v.5, Número Especial, p. 25-36, fev. 2018 
Gestão e Sociedade

Múltiplos Olhares em Ciência da Informação

\begin{tabular}{rrrrr}
145 & 28 & 32 & 205 & 1,82 \\
134 & 29 & 37 & 200 & 1,78 \\
104 & 33 & 25 & 162 & 1,44 \\
122 & 11 & 29 & 162 & 1,44 \\
77 & 41 & 27 & 145 & 1,29 \\
106 & 12 & 9 & 127 & 1,13 \\
83 & 20 & 10 & 113 & 1,00 \\
59 & 7 & 45 & 111 & 0,99 \\
85 & 9 & 12 & 106 & 0,94 \\
81 & 8 & 13 & 102 & 0,91 \\
\hline 285 & 61 & 51 & 397 & 3,52 \\
\hline 110 & 34 & 29 & 173 & 1,54 \\
\hline 0 & 0 & 0 & 0 & 0,00 \\
\hline $\mathbf{8 2 3 3}$ & $\mathbf{1 4 9 3}$ & $\mathbf{1 5 3 9}$ & $\mathbf{1 1 2 6 5}$ & $\mathbf{1 0 0}$ \\
\hline
\end{tabular}

Revista Geografias

Temporalidades

Lamparina - Revista de Ensino de Artes Cênicas

Nova Economia

Revista Teoria \& Sociedade

Revista Ágora: pol. públicas, comunic. e gov. inf.

Revista de Ciências do Estado

Revista Multiface Online

De 50 a 99 interações (5 Revistas)

Até 50 interações (10 revistas)

Nenhuma interação (4 revistas)

Total

8233

A revista "Perspectivas em Ciência da Inf." alcançou maior audiência na atenção online, com 1.646 dados de interação $(14,61 \%)$, seguida da "Revista da Faculdade de Direito da UFMG", com 1.319 (11,71\%), e da "Revista Brasileira de Estudos Políticos", com 1.194 (10,60\%). As ações de "curtir" representam o tipo de interação mais evidente do universo analisado, corresponde a $73,08 \%$ das interações. Os compartilhamentos e comentários tiveram desempenho aproximado e representam $13,66 \%$ e $13,25 \%$, respectivamente. A ação de curtir e o compartilhar é justamente aquelas ligadas ao movimento de legitimar o que está sendo dito, sinalizando concordância e costumam ser associados a uma reação positiva em relação ao conteúdo e o comentário. Equivalem a dizer que há uma possível a discussão em torno dos artigos (ARAÚJO; MURAKAMI, 2016).

Para uma melhor aproximação do universo analisado, tendo em vista o volume de artigos, foi realizado um recorte com os dez mais expressivos, ou seja, um ranking com os artigos que obtiveram os maiores índices altmétricos. Tais artigos podem ser visualizados na Tabela $5 \mathrm{com}$ descrição do título, seus autores, título do periódico, ano de publicação e o número de curtidas (C1), compartilhamentos (C2) e comentários (C3).

Tabela 5. Dez artigos que obtiveram mais atenção online

\begin{tabular}{|c|c|c|c|c|c|c|c|}
\hline Título & Autores & Periódico & Ano & C1 & $\mathrm{C} 2$ & C3 & Total \\
\hline Direito, figura do ódio & José Rodrigo Rodriguez & $\begin{array}{l}\text { Revista } \\
\text { Brasileira de } \\
\text { Estudos } \\
\text { Políticos }\end{array}$ & 2013 & 255 & 59 & 34 & 348 \\
\hline $\begin{array}{l}\text { Aspectos macroscópicos dos } \\
\text { esteatitos encontrados no Santuário } \\
\text { Bom Jesus do Matosinhos, } \\
\text { Congonhas/MG }\end{array}$ & $\begin{array}{l}\text { Mônica Pessoa Neves; } \\
\text { Antônio Gilberto } \\
\text { Costa; Úrsula de } \\
\text { Azevedo Ruchkys }\end{array}$ & $\begin{array}{l}\text { Revista } \\
\text { Geonomos }\end{array}$ & 2016 & 263 & 1 & 54 & 318 \\
\hline $\begin{array}{l}\text { Autobiografia na cena } \\
\text { contemporânea: tensionamentos } \\
\text { entre o real e o ficcional }\end{array}$ & $\begin{array}{l}\text { Gabriela Lirio Gurgel } \\
\text { Monteiro }\end{array}$ & $\begin{array}{l}\text { PÓS: Rev. } \\
\text { Prog. Pós- } \\
\text { graduação } \\
\text { Artes da } \\
\text { EBA/UFMG. }\end{array}$ & 2016 & 280 & 11 & 10 & 301 \\
\hline $\begin{array}{l}\text { Musil e Benjamin: a ética do homem } \\
\text { sem qualidades e o empobrecimento } \\
\text { da experiência }\end{array}$ & $\begin{array}{l}\text { Juliano Garcia } \\
\text { Pessanha; Luciana } \\
\text { Araújo Marques }\end{array}$ & $\begin{array}{l}\text { Cadernos } \\
\text { Benjaminianos }\end{array}$ & 2016 & 158 & 9 & 21 & 188 \\
\hline
\end{tabular}

Ci. Inf. Rev., Maceió, v.5, Número Especial, p. 25-36, fev. 2018 


\begin{tabular}{|c|c|c|c|c|c|c|c|}
\hline $\begin{array}{l}\text { A dramaturgia de Lourdes Ramalho } \\
\text { como expressão da modernidade } \\
\text { teatral brasileira }\end{array}$ & $\begin{array}{l}\text { Diogenes Andre Vieira } \\
\text { Maciel }\end{array}$ & $\begin{array}{l}\text { O Eixo e a } \\
\text { Roda: Revista } \\
\text { de Literatura } \\
\text { Brasileira }\end{array}$ & 2017 & 154 & 11 & 17 & 182 \\
\hline $\begin{array}{l}\text { Para que serve a dupla avaliação } \\
\text { cega por pares? Poder estatal e } \\
\text { autorregulação na avaliação dos } \\
\text { Programas de Pós-Graduação }\end{array}$ & José Rodrigo Rodriguez & $\begin{array}{l}\text { Revista } \\
\text { Brasileira de } \\
\text { Estudos } \\
\text { Políticos }\end{array}$ & 2013 & 153 & 21 & 0 & 174 \\
\hline $\begin{array}{l}\text { Sistema eleitoral, corrupção e } \\
\text { reforma política }\end{array}$ & $\begin{array}{l}\text { Bruno Pinheiro } \\
\text { Wanderley Reis }\end{array}$ & $\begin{array}{l}\text { Revista do } \\
\text { Centro } \\
\text { Acadêmico } \\
\text { Afonso Pena }\end{array}$ & 2014 & 114 & 29 & 17 & 160 \\
\hline $\begin{array}{l}\text { Os significados da prática e da } \\
\text { assistência do futebol amador para } \\
\text { frequentadores de um clube da } \\
\text { cidade de Piracicaba/SP }\end{array}$ & $\begin{array}{l}\text { Milena Avelaneda } \\
\text { Origuela; Cinthia Lopes } \\
\text { da Silva }\end{array}$ & $\begin{array}{l}\text { Revista } \\
\text { Brasileira de } \\
\text { Estudos do } \\
\text { Lazer }\end{array}$ & 2017 & 114 & 3 & 35 & 152 \\
\hline $\begin{array}{l}\text { Caracterização da Prática } \\
\text { Esportiva/Recreativa do Skate em } \\
\text { São Paulo, Paraná e Rio Grande do } \\
\text { Sul }\end{array}$ & $\begin{array}{l}\text { Luana Mari Noda; } \\
\text { Giuliano Gomes de } \\
\text { Assis Pimentel }\end{array}$ & $\begin{array}{l}\text { LICERE - } \\
\text { Rev. Prog. } \\
\text { Pós-graduação } \\
\text { Interdisc. Est. } \\
\text { Lazer }\end{array}$ & 2015 & 120 & 20 & 4 & 144 \\
\hline $\begin{array}{l}\text { Friedrich Engels e o duplo aspecto } \\
\text { da igualdade }\end{array}$ & Vitor Bartoletti Sartori & $\begin{array}{l}\text { Revista da } \\
\text { Faculdade de } \\
\text { Direito da } \\
\text { UFMG }\end{array}$ & 2016 & 130 & 4 & 4 & 138 \\
\hline
\end{tabular}

Fonte: dados da pesquisa (2017)

Conforme esperado de indicadores altmétricos, artigos mais recentes tendem a obter maior atenção online, e consequentemente uma pontuação elevada (ARAUJO; MURAKAMI, 2016). Os artigos apresentados na tabela foram publicados nos anos de 2013 (2), 2014 (1), 2015 (1), 2016 (4) e 2017 (2). Artigos dos anos de 2010 a 2012 tiveram baixa ou nenhuma expressão nas primeiras 100 posições. Mais uma vez, o número de "curtidas" supera consideravelmente os de "compartilhamento" e "comentários".

\section{CONSIDERAÇÕES FINAIS}

Serviços e soluções disponíveis no mercado para aferição de métricas alternativas para produtos da ciência (livros, artigos, revistas, repositórios institucionais, etc) consideram várias fontes de dados de plataformas, mídias sociais e gerenciadores de referências; exigem padrões para seu monitoramento, e; requerem um investimento e custo relativamente alto que nem sempre as revistas dispõem de recursos para aplicar.

No primeiro aspecto é necessário melhor compreensão de cada fonte e as implicações de seu uso para a comunicação científica, no segundo, a preocupação é quanto a infraestrutura de informação de pesquisa e seus aspectos técnicos e normativos, ficando, no terceiro, reflexões quanto ao fomento e sustentabilidade financeira de revistas.

Os portais que estiverem atentos aos critérios de qualificação de seus periódicos devem considerar essas questões, seja pela própria necessidade de compreensão do que são as métricas alternativas e $\mathrm{o}$ que representam para suas revistas, ou para atender a critérios de presença online e aferição de altmetria de sua produção, o que tem sido exigido por indexadores como SciELO e Latindex (ARAÚJO, 2015).

No estudo apresentado, considera-se, mesmo que de forma preliminar, que foram atendidos os três aspectos com a solução utilizada na pesquisa. Primeiramente, pela 
dedicação à compreensão e análise de uma fonte, no caso, o Facebook. Em segundo lugar, contorna-se a ausência de identificadores como o DOI com consultas por URL via Facebook API, que não demanda custo, embora exija um pouco de conhecimento técnico para as parametrizações. Um total de quatro revistas não apresentou dados altmétricos quando consultadas pelas URLs dos seus artigos, o que precisa ser melhor investigado.
Considera-se as interações com conteúdo de artigos científicos no Facebook como ricas fontes de dados altmétricos, as quais podem agregar informações de impacto social de publicações das revistas do Portal Periódicos UFMG, fornecendo uma visão adicional sobre o desempenho científico dos artigos quando curtidos, compartilhados ou comentados.

\title{
ONLINE ATTENTION OF THE UFMG SCIENTIFIC JOURNAL GATEWAY: FACEBOOK ALTMETRIC DATA ANALYSIS
}

\begin{abstract}
This paper discusses the academic journals of the Federal University of Minas Gerais gateway as one of the actions of the politics of periodical detachment and presents some of its results of action. As part of the development actions of the journals gateway interaction data from Facebook as indicative of online attention and altmetrics of scientific production. It analyzes based on an exploratory study the social impact of articles of the UFMG scientific journals gateway according to its data of tastings, shares and comments. We analyzed 46 journals with publication in the period from 2010 to 2017, which provided 6,437 articles, and only 543 of them had interaction data. Online attention is characterized according to its distribution by range of interaction, area of knowledge, period and analyzed by the performance of journals and articles.
\end{abstract}

\section{Keywords}

Altmetria. Online attention. Facebook. UFMG scientific journals gateway.

Artigo recebido em 15/01/2018 e aceito para publicação em 17/02/2018

\section{REFERÊNCIAS}

ARAUJO, R. F.; MURAKAMI, T. R. M.; ANDRADE, R. L. V. Repertório da produção periódica brasileira de Ciência da Informação: indícios embrionários. Pesquisa Brasileira em Ciência da Informação e Biblioteconomia, v. 11, p. 44-53, 2016. Disponível em: <

http://periodicos.ufpb.br/ojs/index.php/p $\mathrm{bcib} /$ article/view/28072 $>$. Acesso em: 07 ago. 2017.

ARAUjO, R. F.; MURAKAMI, T. R. M. Atenção online de artigos de ciência da informação: análise a partir de dados altmétricos do Facebook. In: ENCONTRO BRASILEIRO DE BIBLIOMETRIA E CIENTOMETRIA, v. 5, 2016, São Paulo. Anais... São Paulo: ECA/USP, 2016. Disponível em: $<$ https://doi.org/10.6084/m9.figshare.3479 249.v1>. Acesso em: 22 jul. 2017.
ARAUJO, R. F. Marketing científico digital e métricas alternativas para periódicos: da visibilidade ao engajamento. Perspectivas em Ciência da Informação, Belo Horizonte, v. 20, p. 67-84, 2015. Disponível em: $<\underline{\text { http://dx.doi.org/10.1590/1981- }}$ 5344/2402 >. Acesso em: 03 set. 2016.

BORNMANN, L. Do altmetrics point to the broader impact of research? An overview of benefits and disadvantages of altmetrics. Journal of Informetrics, v. 8, n. 4, p. 895903, out., 2014. Disponível em: $<$ https://doi.org/10.1016/i.joi.2014.09.005> . Acesso em: 03 set. 2016.

BRITO, Ronnie Fagundes de et. al. Guia do usuário do Digital Object Identifier. Brasília: IBICT, 2016. Disponível em: $<$ https://www.abecbrasil.org.br/arquivos/ Guia usuario DOI-online3.pdf $>$. Acesso em: 12 jan. 2018. 
GARRIDO, Isadora dos Santos; RODRIGUES, Rosangela Schwarz. Portais de periódicos científicos online: organização institucional das publicações. Perspectivas em Ciência da Informação, Belo Horizonte, v. 15, n. 2, p. 56-72, maio/ago. $2010 . \quad$ Disponível em: $<\underline{\text { http://portaldeperiodicos.eci.ufmg.br/ind }}$ ex.php/pci/article/view/943/732> Acesso em: 08 jan. 2018.

GULKA, Juliana Aparecida; LUCAS, Elaine Rosangela de Oliveira. Presença digital em portais de periódicos: uma proposta de análise. Em Questão, Porto Alegre, v. 23, p. 159-179, edição especial, 5 EBBC, 2017. Disponível em:

$<$ http://dx.doi.org/10.19132/1808-

5245230.159-179 >. Acesso em: 10 jan. 2018.

IAMARINO, A. Você compartilha, eu curto e nós geramos métricas. SciELO em Perspectiva. Ago., 2013. Disponível em: $<$ http://blog.scielo.org/blog/2013/08/08/ voce-compartilha-eu-curto-e-nos-geramosmetricas/>. Acesso em: 03 set. 2016.

RINGELHAN, S.; WOLLERSHEIM, J.; WELPE, I. M. I Like, I Cite? Do Facebook Likes Predict the Impact of Scientific Work? PLoS ONE, v.10, n.8, ago., 2015. Disponível em:

$<\underline{\text { https://doi:10.1371/journal.pone.0134389 }}$

>. Acesso em: 03 set. 2016.

i Versão revista e ampliada do Trabalho "Atenção online de artigos do portal periódicos UFMG: análise dos dados do Facebook" apresentado no evento ABEC MEETING, 6-9, novembro, Curitiba, PR, 2017.
RODRIGUES, R.; FACHIN, G. R. B. A comunicação científica e o uso de portais: estudo. In: ENCONTRO NACIONAL DE PESQUISA EM CIÊNCIA DA INFORMAÇÃO - ENANCIB, 9., 2008, Rio de Janeiro. Anais... Rio de Janeiro. ENANCIB; 2008. $<$ http://enancib.ibict.br/index.php/enancib Lixenancib/paper/viewFile/3113/2239> Acesso em: 08 jan. 2018.

RODRIGUES, Rosângela Schwarz; FACHIN, Gleisy Regina Bories. Portal de periódicos científicos: um trabalho multidisciplinar. Transinformação, Campinas, v. 22, n. 1, p. 33-45, jan./abr., $2010 . \quad$ Disponível em: $<$ http://dx.doi.org/10.1590/S010337862010000100003>. Acesso em: 03 set. 2016.

QUALIS: Periódicos. 2018. Disponível em $<$ https://sucupira.capes.gov.br/sucupira/pu blic/index.jsf;jsessionid=AiuUPYw6qZw14 v4KwWRfZ53J.sucupira-218>. Acesso em: 12 jan. 2018. 